\title{
Alkaloid defenses of co-mimics in a putative Müllerian mimetic radiation
}

\author{
Adam MM Stuckert $^{1 *}$, Ralph A Saporito ${ }^{2}$, Pablo J Venegas ${ }^{3}$ and Kyle Summers ${ }^{1}$
}

\begin{abstract}
Background: Polytypism in aposematic species is unlikely according to theory, but commonly seen in nature. Ranitomeya imitator is a poison frog species exhibiting polytypic mimicry of three congeneric model species ( $R$. fantastica, R. summersi, and two morphs of $R$. variabilis) across four allopatric populations (a "mimetic radiation"). In order to investigate chemical defenses in this system, a key prediction of Müllerian mimicry, we analyzed the alkaloids of both models and mimics from four allopatric populations.

Results: In this study we demonstrate distinct differences in alkaloid profiles between co-mimetic species within allopatric populations. We further demonstrate that $R$. imitator has a greater number of distinct alkaloid types than the model species and more total alkaloids in all but one population.

Conclusions: Given that $R$. imitator is the more abundant species in these populations, $R$. imitator is likely driving the majority of predator-learned avoidance in these complexes. The success of Ranitomeya imitator as a putative advergent mimic may be a direct result of differences in alkaloid sequestration. Furthermore, we propose that automimicry within co-mimetic species is an important avenue of research.
\end{abstract}

Keywords: Alkaloids, Aposematism, Dendrobatids, Müllerian mimicry, Polytypism, Ranitomeya imitator

\section{Background}

Poison frogs provide a classic example of aposematism, in that they possess warning colors and/or patterns directed towards predators and are protected by alkaloidbased chemical defenses [1,2]. Alkaloid defenses have been detected in five families of poison frogs: Dendrobatidae [1,3], Mantellidae [4-6], Bufonidae in the genus Melanophryniscus [6-8], Myobatrachidae in the genus Psuedophryne [6], and recently in diminutive Cuban members of Eleutherodactylidae [9]. For a full review of the chemical sequestration in poison frog families see [10].

The family Dendrobatidae contains a high diversity of frog species and alkaloids [11,12], providing a number of unique opportunities to study the link between aposematism and chemical defense. Alkaloid defenses in all poison frogs (including Dendrobatidae) are sequestered from an arthropod diet [3], consisting primarily of mites, ants, beetles, and millipedes (reviewed in [13]). Accompanying the ability to sequester alkaloid defenses, many species exhibit

\footnotetext{
* Correspondence: stuckerta10@students.ecu.edu

'Department of Biology, East Carolina University, 1000 E. Fifth St, Greenville, NC 27858, USA

Full list of author information is available at the end of the article
}

substantial polytypism in color and pattern across their geographic range [14]. The presence of such polytypisms appears to contradict certain theoretical predictions, in particular, the hypothesis that predators exert strong selective pressure to maintain monomorphism as a result of learned avoidance [15]. Indeed, a number of studies using clay model replicas of dendrobatid frogs have shown that natural predators exert purifying selection, and "favor" one color morph within populations [16,17]; however, one study indicated that at low prey densities the effect of this stabilizing selection is limited [18]. In addition to phenotypic variation, many dendrobatids exhibit substantial variation in alkaloid defense, both geographically and temporally $[1,3,19]$, and across and within populations [20].

Ranitomeya imitator [21] is a polytypic poison frog species that appears to have gone through a rapid 'mimetic radiation' to adverge on to the morphological appearance of multiple congeneric species throughout its range [22-25]; however see [26]. Advergence is the process whereby one species evolves to appear similar to another (established) species, as opposed to convergence, a process in which two or more species evolve towards monomorphism [22,26]. There are four described allopatric mimetic populations of 
R. imitator in the departments of San Martin and Loreto in northern Peru (see Figure 1) [12,24]. Ranitomeya imitator was described as the advergent 'mimic' due to extremely short branch lengths in phylogenetic trees compared to its congeneric co-mimetic species $R$. variabilis (Zimmermann and Zimmermann) and R. summersi [12,22,23]. Chouteau et al. [26] raised concerns about the usage of these terms based on genetic differentiation between two close populations of co-mimetic $R$. imitator and $R$. variabilis. However, phylogeographic evidence provides additional support for the advergence hypothesis, with $R$. imitator mimicking two other (distantly related) species in other localities [12,22-24]. There is also evidence for recent divergence under selection in $R$. imitator [24], and evidence for multiple independent lineages of a highland spotted morph of $R$. variabilis, even in areas well outside the range of $R$. imitator [12]. Although we typically refer to these species as "co-mimics" throughout the paper, when relevant we use the term 'mimic' to refer to $R$. imitator and 'model' to refer to co-mimetic congeners (R. fantastica, R. summersi, and $R$. variabilis).

The mimetic complexes involving Ranitomeya imitator are considered an example of a Müllerian mimicry system in vertebrates $[12,15,22,24]$, and provide a close parallel to the well-known Müllerian mimicry systems of Heliconius butterflies [27,28]. However, the hypothesis of Müllerian mimicry in Ranitomeya was only recently tested in a study describing reciprocal learned avoidance by predators between co-mimetic $R$. variabilis and $R$. imitator [29]. Reciprocal learned avoidance is a key tenet of Müllerian mimicry, and the results of Stuckert et al. [29] support the hypothesis of a Müllerian mimicry systemthe first known in anurans. Other putative Müllerian complexes exist in anurans (e.g., mantellids [30], Amereega picta (Tschudi) and Leptodactylus lineatus (Schneider) [31], and among other members of the genus Ranitomeya [12]), but these have not been experimentally verified.

Another key tenet of the hypothesis of Müllerian mimicry is that co-mimetic species all possess a secondary defense (e.g., alkaloid defenses in Ranitomeya) against predators. Learned avoidance by predators in this system is seemingly a good indication of the presence of an alkaloid defense [29]. However, here, we explicitly test each mimetic species for the presence, quantity, and identity of alkaloids. The presence of alkaloids in these species would provide significant support for the hypothesis that this is a Müllerian mimicry system.

Because alkaloid defenses in poison frogs are sequestered from dietary sources $[3,13]$, and the species we are examining are congenerics with similar ecologies, we would expect sympatric Müllerian co-mimics in this system to possess similar defense profiles. Alternatively, mimetic species that differ in their chemical protection may not behave as Müllerian mimics, even if they are both chemically defended. Instead, differences in defensive chemicals between species may decrease the efficiency of

Allopatric Mimicry Complexes

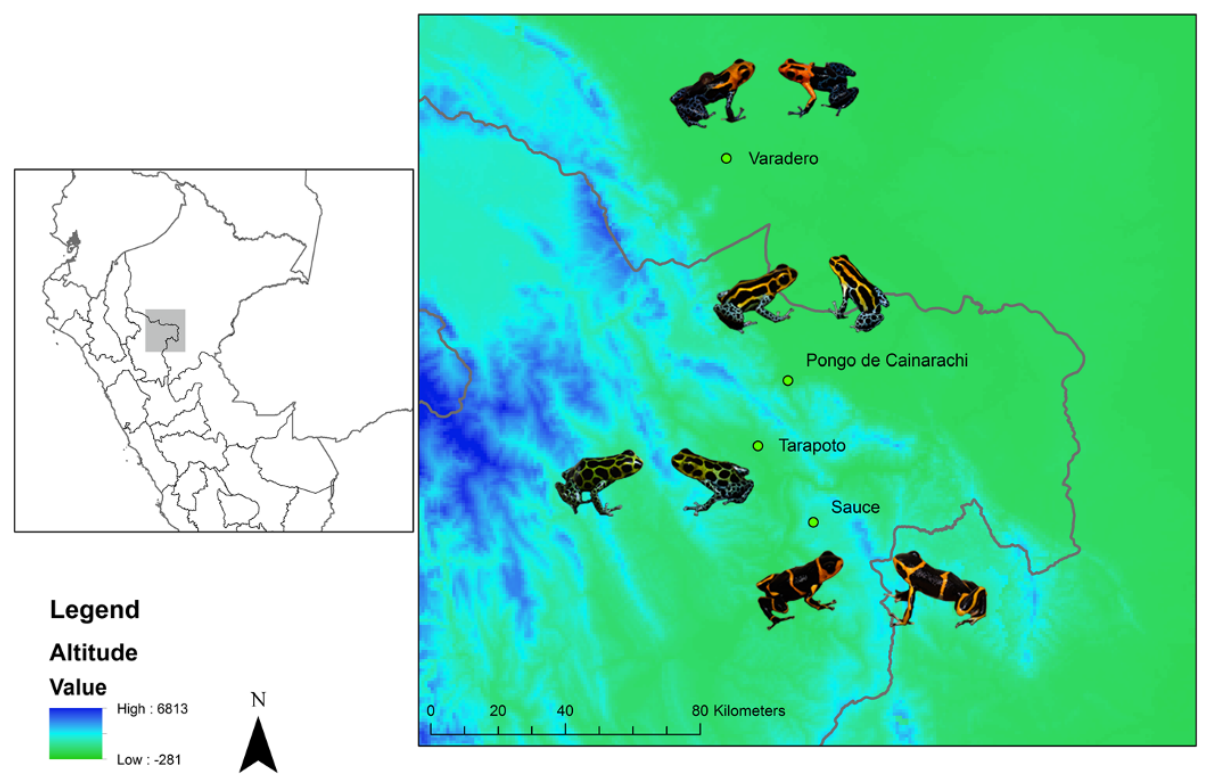

Figure 1 Sampling species and localities for this study in the departments of San Martin and Loreto, Peru. From North to South: $R$ imitator and R. fantastica from Varadero, Loreto; R. imitator and R. variabilis from Pongo de Cainarachi, San Martin; R. imitator and R. variabilis from Tarapoto, San Martin; and R. imitator and R. summersi from Sauce, San Martin. Ranitomeya imitator is the left species in each pairing, and the model species are on the right. 
learned avoidance, in particular when predators sample prey that are less toxic (i.e., palatable) than individuals sampled previously [15,32]; however see [33] for counterarguments. In the present study, we further examine the hypothesis that the co-mimetic species are Müllerian mimicry systems by examining alkaloid defenses between co-mimetic species and broadening the scope of examined mimetic complexes.

To investigate the relationships between chemical defenses among co-mimetic species, we characterized the alkaloids of $R$. imitator and its congeneric co-mimics $(R$. variabilis, $R$. fantastica, and $R$. summersi) in four allopatric mimetic complexes. This study covers the majority of the range of $R$. imitator and examines all known mimetic complexes of the species. In this paper, we present a detailed study of the chemical secondary defenses in the genus Ranitomeya, as well as the only study of chemical secondary defenses in the context of Müllerian mimicry in amphibians. Our study provides valuable insight into the workings of the only confirmed system of Müllerian mimicry in anurans. It thus has substantial implications for our understanding of mimicry in other mimetic anuran systems, for parallel systems in Heliconius butterflies, and for Müllerian mimicry in general.

\section{Results}

Alkaloid composition varied significantly among sites (Global $\mathrm{R}=0.331 ; \mathrm{p}=0.001$; Figure 2), and there was a significant difference in alkaloid composition between species within each site (Tarapoto, San Martin: Global $\mathrm{R}=0.504, \mathrm{p}=0.016$; Pongo de Cainarachi, San Martin: Global $\mathrm{R}=0.424, \mathrm{p}=0.016$; Sauce, San Martin: Global $\mathrm{R}=0.76 ; \mathrm{p}=0.008$; Varadero, Loreto: Global $\mathrm{R}=0.636$; $\mathrm{p}=0.008$; Figure 2).
Ranitomeya imitator had a greater number of alkaloids than the co-existing mimetic species for each site. This difference was statistically significant in the Sauce banded morph of $R$. imitator and $R$. summersi $\left(\mathrm{t}_{8}=4.451, \mathrm{p}=\right.$ 0.002 ) and the Varadero orange-headed morph of $R$. imitator and $R$. fantastica $\left(\mathrm{t}_{8}=2.757, \mathrm{p}=0.025\right)$, and was suggestive of a trend in the Tarapoto spotted morph of $R$. imitator and $R$. variabilis $\left(\mathrm{t}_{8}=1.857, \mathrm{p}=0.100\right)$ and the Pongo de Cainarachi striped population of $R$. imitator and $R$. variabilis $\left(\mathrm{t}_{8}=1.549, \mathrm{p}=0.160\right.$; Figure 3$)$.

Ranitomeya imitator also had a greater quantity of alkaloids than its Müllerian co-mimic in every site except for the Varadero population (mimetic with $R$. fantastica, $\left.\mathrm{t}_{8}=-1.355, \mathrm{p}=0.213\right)$. The variation in alkaloid quantity within mimetic species within a site is vast, however, and our sample size was low in an effort to reduce the number of frogs sacrificed. Thus, the difference is only statistically significant between $R$. imitator and $R$. summersi from Sauce $\left(\mathrm{t}_{8}=2.671, \mathrm{p}=0.028\right)$ and the Tarapoto site with $R$. imitator and $R$. variabilis $\left(\mathrm{t}_{8}=2.339, \mathrm{p}=0.047\right)$. The Pongo site (also $R$. imitator and $R$. variabilis) was not significant $\left(\mathrm{t}_{8}=1.071, \mathrm{p}=0.315\right.$; Figure 4).

A total of 108 alkaloids, representing 13 different structural classes, were identified from skin extracts examined in this study. The most common and widespread alkaloids, found in at least one individual from each population, were the histrionicotoxins (HTX) 235A, 259A, 261 A, and 285A (HTX 291A was found in all populations except Tarapato, San Martin), the 2,5-disubstituted decahydroquinolines (DHQ) 219A and 243A, and the 3,5-disubstituted indolizidine (3,5-I) 223AB. All of these alkaloids are likely derived from dietary ants $[13,10]$, suggesting that ants play a major role in the chemical defenses of these frog populations. Data on the class, type, and quantity of alkaloids present within individual frogs are available in Additional file 1.
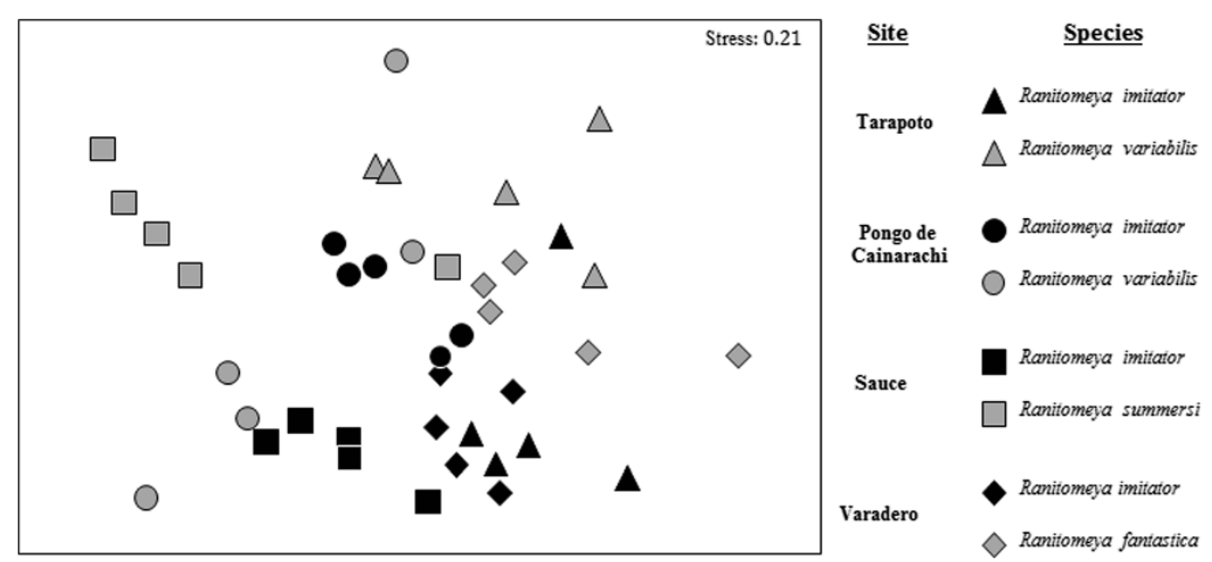

Figure 2 nMDS plot of alkaloid composition among individual frogs and species from different sites. Each symbol represents an individual frog and species from a specific site, and the distance between symbols represents the difference in alkaloid composition. Alkaloid composition varies significantly among sites (Global $R=0.331 ; p=0.001)$, and between species within each site $(p<0.05$ for all within site comparisons). 


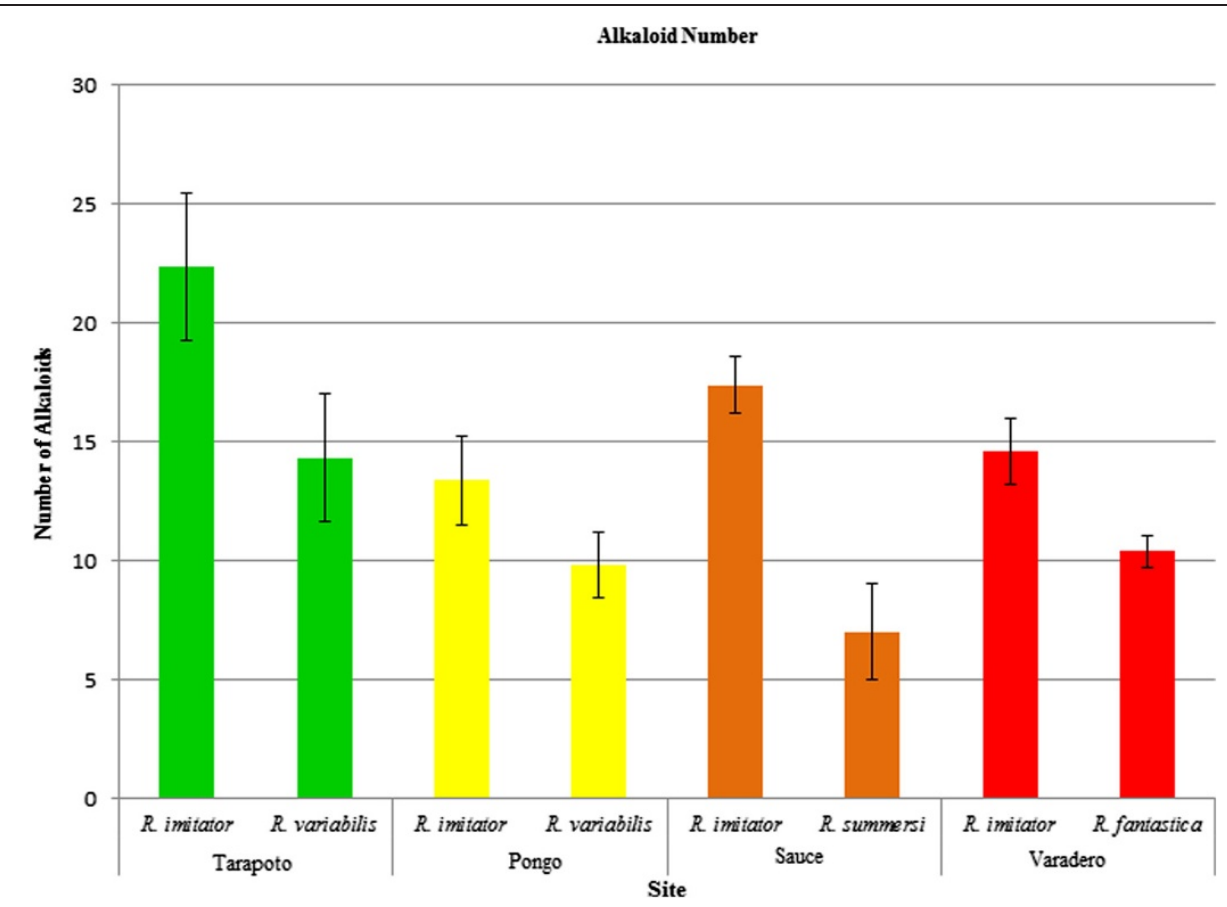

Figure 3 Mean number of alkaloid types per species/site. Error bars represent standard error of the mean

\section{Discussion}

Numerous authors have postulated that the mimetic complexes of Ranitomeya represent a Müllerian system (e.g., $[12,15,22-24])$, and recent experimental evidence supports the hypothesis of Müllerian mimicry based on learned avoidance by predators $[17,29]$. One key prediction of Müllerian mimicry is the presence of chemical defenses in all mimetic species. Our data demonstrate for the first time that all Ranitomeya species involved in the mimetic complexes possess alkaloid defenses. This is a key tenet of

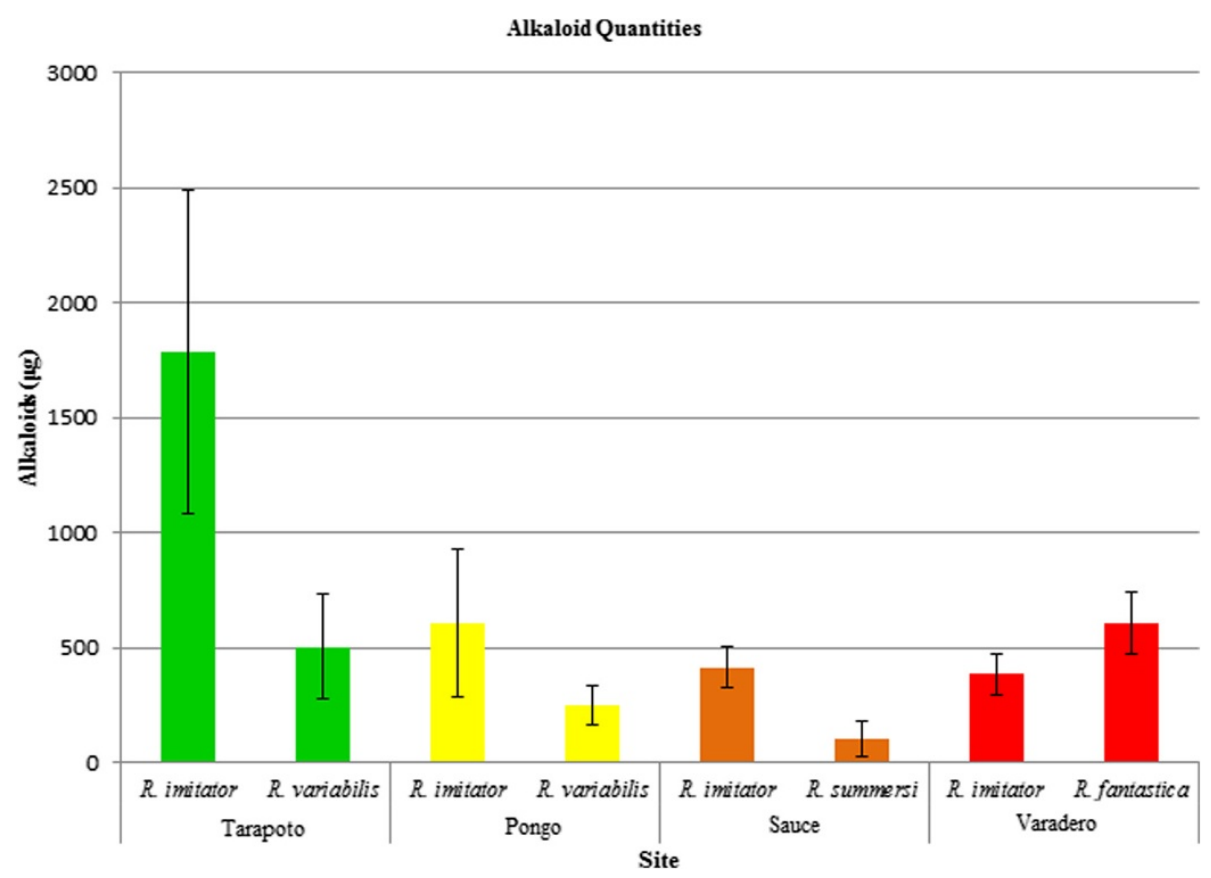

Figure 4 Mean alkaloid quantities per species/site, corrected for frog mass. Error bars represent standard error of the mean. 
Müllerian mimicry, and chemically defended co-mimetic species are likely to contribute to learned avoidance by predators. These findings provide further support of the hypothesis of Müllerian mimicry and evidence that all of these allopatric populations are likely an example of Müllerian mimicry.

Prior work examining mimicry among these mimetic species has posited that $R$. variabilis is less palatable to predators when compared to $R$. imitator [29]. Interestingly, the alkaloid data presented here illustrate that $R$. imitator contains significantly more alkaloids than its model species within most localities, suggesting that differences in palatability may not always be related to the number or quantity of alkaloids, but rather the specific types of alkaloids present in a frog. The manner in which individual alkaloids affect potential predators are virtually unknown, and similarly no data exist on the effects of complex alkaloid mixtures on potential predators. It is likely that different alkaloids possess different levels of palatability, and therefore differences in the presence or quantity of these particular alkaloids are most important to predator avoidance. Stuckert et al. [29] found no evidence that $R$. imitator elicited a greater avoidance response than the co-mimetic $R$. variabilis, suggesting that not all the differences in alkaloids are strongly correlated with predator response and, importantly, learned avoidance by predators.

There are two possible mechanisms to explain the difference in alkaloids between $R$. imitator and its congeners. The first is a genetic difference that might allow for more rapid or efficient sequestration in $R$. imitator when compared to $R$. variabilis. Although an intriguing possibility, this explanation seems improbable due to the close phylogenetic relationships between these species $[11,12]$. It is, however, possible that genes related to alkaloid sequestration are under a strong selective force and are rapidly evolving. The second, and more likely, explanation is a difference in arthropod diet, primarily resulting from differential microhabitat usage. Although these co-mimetic species frequently co-occur in the same habitats, Ranitomeya imitator is more commonly found in early secondary forests or disturbed portions of forest, due to the abundance of reproductive resources (e.g., Heliconia and Diffenbachia $s p$ ), whereas the co-mimetic model species ( $R$. fantastica, $R$. summersi, and $R$. variabilis) are typically found in more pristine forest (AMMS pers. obs.) and are more arboreal [34]. The difference in microhabitat usage between these species may put $R$. imitator in contact with increased quantities of ant-derived toxins (e.g., DHQs, HTXs, and 3,5-Is) more frequently than its comimetic species. This is similar to Mantella baroni, which has been shown to possess more alkaloids in disturbed habitats [35]. Indeed, the data presented here indicate a significant difference in alkaloid composition between $R$. imitator and its model species, with much of this being driven by differences in quantity of the structurally similar ant-derived alkaloids. A detailed analysis of frog diet and arthropod abundance/distribution in this system would provide further insight on the observed differences in alkaloid defenses between species in this study.

Another possibility is that an increase in abundance of $R$. imitator compared to its initial mimetic radiation has decreased the selective pressure on its co-mimetic model species. Ranitomeya imitator adverged on to the appearance of already established congeneric species (Symula et al. [22,23]; however see [26] and above for discussion of this hypothesis), and presumably, $R$. imitator was under selective pressure to mimic already established species during this mimetic radiation [25]. However, since becoming established, $R$. imitator has become more abundant than its sympatric model species [25], thus we expect predators to come in to contact with $R$. imitator more frequently than the co-mimetic model species. As a result, the majority of predator learned avoidance will be driven by $R$. imitator, likely benefitting the rarer co-mimetic species [36]. If alkaloids are in fact costly to sequester [37,38], and dietary specialization is associated with increased metabolic rates [39], we might expect a reduction in alkaloid defenses of the co-mimetic species. Although speculative, the proliferation of $R$. imitator (and the associated increase of the frequency dependent mimetic signal) could reduce the pressure on these less common co-mimetic species to maintain high levels of alkaloid defense, thus allowing them to allocate resources away from sequestering alkaloids and towards reaching sexual maturity and reproduction.

Intriguingly, the Varadero locality where $R$. imitator is co-mimetic with $R$. fantastica is the only population in which the model species possessed a slightly greater quantity of alkaloids than $R$. imitator (although this difference was not statistically significant). Ranitomeya fantastica is present throughout much of the range of $R$. imitator included in this study (e.g., the Tarapoto and Pongo de Cainarachi populations), yet $R$. imitator evolved to mimic $R$. variabilis in these areas. Near Pongo de Cainarachi there is a population in which $R$. imitator, $R$. variabilis, and $R$. fantastica have all evolved a striped morph. However, this tri-mimicry occurs over a very restricted range, and $R$. fantastica is highly polytypic throughout the rest of the range of the striped morph of $R$. variabilis and R. imitator. As a result, we think that $R$. variabilis is the species that drove the evolution of this tri-mimicry. Given our alkaloid data, it remains unclear why $R$. imitator adverged on to $R$. variabilis throughout most of its range as opposed to $R$. fantastica, which possesses more alkaloids than $R$. imitator in the sympatric site we sampled (although this may not correlate with toxicity per se, see Discussion above). We propose that this occurred due 
to the greater phenotypic variation found in $R$. fantastica throughout this range, and because $R$. variabilis is more commonly encountered than $R$. fantastica in these areas [25], although it is possible that $R$. imitator looked more similar to the local $R$. variabilis than $R$. fantastica when they initially came in to contact. Aposematism and mimicry are frequency-dependent [15], thus we would expect a more abundant (or more commonly encountered species) to be a better model for an advergent mimic. If $R$. imitator evolved to mimic $R$. variabilis instead of $R$. fantastica due to abundance, this may indicate that differences in encounter rates can significantly influence the evolution of Müllerian mimicry, as predicted by theory.

Our data also indicate substantial intrapopulation variation in the alkaloid defenses between individuals (see nMDS plot in Figure 2). Similar results have been found in other poison frogs $[1,3,19]$. It is possible that automimicry in these mimetic complexes, particularly within $R$. imitator, may play a major role in both educating predators and maintaining learned avoidance in predators. Automimicry describes the existence of non-defended prey in sympatry with defended conspecifics $[40,41]$, but the effects may be similar for species in which individuals vary greatly in their chemical defenses. Poison frogs sequester alkaloids from dietary sources [3] and the accumulation of these toxins likely results in automimicry within poison frog systems $[19,42]$. Automimicry is perhaps unsurprising in poison frog systems given that arthropod systems also exhibit substantial variation in toxicity and are automimetic (reviewed in [43]). Variation in alkaloid defenses within populations of poison frogs may result from the additive effect of temporal sequestration throughout life and patchy prey availability. Automimicry may be an important avenue of future research and we encourage theoretical studies of comimetic species that add a component of automimicry to the models.

\section{Conclusions}

This study presents the most complete examination of alkaloid defense in the genus Ranitomeya to date, including analyses of four allopatric mimetic complexes of congenerics. This study demonstrates that all species from these allopatric mimetic complexes possess alkaloids, which is a key tenet of the hypothesis of Müllerian mimicry. Thus, these data provide further support of the hypothesis of Müllerian mimicry in these allopatric complexes. Coupled with prior data indicating reciprocal learned avoidance by predators in this system $[17,29]$ this provides very strong evidence that these mimetic complexes are Müllerian in nature. We further provide evidence that raw alkaloid data may not correlate well with unpalatability (i.e., avoidance) from a predator's perspective and additionally propose that automimicry may be acting in this system due to high levels of intrapopulation variation in alkaloid profiles.

\section{Methods}

Specimens were collected from four sites within the departments of San Martin and Loreto, Peru during January and February 2012 (see Figure 1). These collections included $5 R$. imitator and $5 R$. variabilis from near Tarapoto, San Martin (18 January); $5 R$. imitator and $5 R$. variabilis from Pongo de Cainarachi, San Martin (12-15 January); 5 R. summersi and 5 R. imitator from Sauce, San Martin (24-27 January); and 5 R. imitator and 5 R. fantastica from Varadero, Loreto (8-10 February). After collection, frogs were euthanized and skins were placed in $4 \mathrm{~mL}$, Teflon-lined glass vials filled with $100 \%$ methanol. Specimens were placed in the CORBIDI Herpetological Collection, Lima, Peru. Research permits were obtained through DGFFS in Lima, Peru (Resolución Directoral $\mathrm{N}^{\circ}$ 033-2011-AG-DGFFS-DGEFFS) and our study protocol was approved by East Carolina University's Institutional Animal Use and Care Committee (permit \#D225). All work presented herein complied with the guidelines set forth by these governing agencies. Export permits are CARTA No 1312-2011 - AG DGFFS - DGEFFS.

Individual alkaloid fractions were prepared from methanol extracts of individual skin. For each sample $10 \mu \mathrm{g}$ of nicotine ((-)-nicotine $\geq 99 \%$, Sigma-Aldrich, Milwaukee, Wisconsin) in a methanol solution (internal standard) and $50 \mu \mathrm{L}$ of $1 \mathrm{~N} \mathrm{HCl}$ was added to $1 \mathrm{~mL}$ of the original $\mathrm{MeOH}$ extract. The combined $\mathrm{MeOH}$ extract was then concentrated with $\mathrm{N}_{2}$ to $100 \mu \mathrm{L}$ and then diluted with $200 \mu \mathrm{L}$ of water. The solution was extracted 4 times, each time with $300 \mu \mathrm{L}$ of hexane. The $\mathrm{HCl}$ fraction was then basified with saturated $\mathrm{NaHCO}_{3}$, followed by extraction 3 times, each time with $300 \mu \mathrm{L}$ of ethyl acetate. The combined ethyl acetate fractions were then dried with anhydrous $\mathrm{Na}_{2} \mathrm{SO}_{4}$ and evaporated to $100 \mu \mathrm{L}$.

Gas chromatography-mass spectrometry (GC-MS) analysis was performed on a Varian Saturn $2100 \mathrm{~T}$ ion trap MS instrument coupled to a Varian 3900 GC with a $30 \mathrm{~m} \times 0.25 \mathrm{~mm}$ i.d. Varian Factor Four VF- $5 \mathrm{~ms}$ fused silica column. GC separation of alkaloids was achieved using a temperature program from 100 to $280^{\circ} \mathrm{C}$ at a rate of $10^{\circ} \mathrm{C}$ per minute with $\mathrm{He}$ as the carrier gas $(1 \mathrm{~mL} / \mathrm{min})$. Each alkaloid fraction was analyzed with both electron impact MS and chemical ionization MS with methanol as the reagent gas.

Individual alkaloids were identified by comparing the observed MS properties and GC retention times with those of previously reported anuran alkaloids [44]. Anuran alkaloids have been assigned code names that consist of a bold-faced number corresponding to the nominal mass and a bold-faced letter to distinguish alkaloids of the same 
nominal mass [44]. To determine the quantity of alkaloids in frog skins, observed alkaloid peak areas were compared to the peak area of the nicotine internal standard, using a Varian MS Workstation v.6.9 SPI. Trace alkaloid peaks under $0.5 \mu \mathrm{g}$ were excluded from our analyses.

The number and quantity of alkaloids were compared among species within a sampling site as well as between sites. The quantity of alkaloids per individual frog was corrected for frog mass and statistical tests use these corrected quantities for examining the alkaloid quantities unless otherwise noted. Independent samples t-tests were performed to compare the number and quantity of alkaloids between species within a sampling location. These statistical analyses were performed in SPSS v. 19. Non-metric multidimensional scaling (nMDS) was used to graphically visualize patterns of alkaloid composition (a combined measure of the type, number, and quantity of alkaloids) in frogs within and among sites. Analysis of similarity (ANOSIM) was used to detect differences in alkaloid composition among sites and between species within a site. All nMDS and ANOSIM analyses are based on Bray-Curtis dissimilarity matrices, and were performed using PRIMER-E version 5.

\section{Additional file}

\section{Additional file 1: Alkaloid data.}

\section{Competing interests}

We hereby confirm that we have no conflicts of interest.

\section{Authors' contributions}

AS participated in project design, conducted field work, and participated in lab work, data analysis, and manuscript writing. RS participated in project design, lab work, data analysis, and manuscript writing. PV participated in project design and manuscript writing. KS participated in project design and manuscript writing. All authors have read and approved the final manuscript.

\section{Acknowledgement}

We would like to thank Jason Brown for his input on this manuscript. Financial assistance was provided by a grant to KS by National Geographic Society (8751-10), partial assistance to AS by East Carolina University in the form of a Next Step Scholarship, and a Kresge Challenge Grant awarded to John Carroll University.

\section{Author details}

${ }^{1}$ Department of Biology, East Carolina University, 1000 E. Fifth St, Greenville, NC 27858, USA. ²Department of Biology, John Carroll University, University Heights, Ohio 44118, USA. ²División de Herpetología-Centro de Ornitología y Biodiversidad (CORBIDI), Santa Rita Nº5 Of. 202, Urb. Huertos de San Antonio, Surco, Lima, Perú.

Received: 29 January 2014 Accepted: 31 March 2014 Published: 4 April 2014

\section{References}

1. Daly JW, Myers CW: Toxicity of Panamanian Poison Frogs (Dendrobates): Some Biological and Chemical Aspects. Science (80-) 1967, 156(970):973.

2. Saporito RA, Zuercher R, Roberts M, Gerow KG, Donnelly MA: Experimental Evidence for Aposematism in the Dendrobatid Poison Frog Oophaga pumilio. Copeia 2007, 4:1006-1011.
3. Daly JW, Secunda SI, Garraffo HM, Spande TF, Wisnieski A, Cover JF Jr: An uptake system for dietary alkaloids in poison frogs (Dendrobatidae). Toxicon 1994, 32:657-663.

4. Garraffo HM, Caceres J, Daly JW, Spande TF: Alkaloids in Madagascan Frogs (Mantella): Pumiliotoxins, Indolizidines, Quinolizidines, and Pyrrolizidines. J Nat Prod 1993, 56:1016-1038.

5. Clark VC, Raxworthy CJ, Rakotomalala V, Sierwald P, Fisher BL: Convergent evolution of chemical defense in poison frogs and arthropod prey between Madagascar and the Neotropics. Proc Natl Acad Sci U S A 2005, 102:11617-22.

6. Daly JW, Highet RJ, Myers CW: Occurrence of skin alkaloids in non-dendrobatid frogs from Brazil (Bufonidae), Australia (Myobatrachidae) and Madagascar (Mantellinae). Toxicon 1984, 22:905-919.

7. Daly JW, Wilham JM, Spande TF, Garraffo HM, Gil RR, Silva GL, Vaira M: Alkaloids in bufonid toads (melanophryniscus): temporal and geographic determinants for two argentinian species. J Chem Ecol 2007, 33:871-87.

8. Daly JW, Garraffo HM, Spande TF, Yeh HJC, Peltzer PM, Cacivio PM, Baldo JD, Faivovich J: Indolizidine $239 \mathrm{Q}$ and quinolizidine $275 \mathrm{I}$. Major alkaloids in two Argentinian bufonid toads (Melanophryniscus). Toxicon 2008, 52:858-70.

9. Rodríguez A, Poth D, Schulz S, Vences M: Discovery of skin alkaloids in a miniaturized eleutherodactylid frog from Cuba. Biol Lett 2011, 7:414-8.

10. Saporito RA, Donnelly MA, Spande TF, Garraffo HM: A review of chemical ecology in poison frogs. Chemoecology 2012, 22:159-168.

11. Grant T, Frost DR, Caldwell JP, Gagliardo R, Haddad CFB, Kok PJR, Means DB, Noonan BP, Schargel WE, Wheeler WC: Phylogenetic Systematics of DartPoison Frogs and Their Relatives (Amphibia: Athesphatanura: Dendrobatidae). Bull Am Museum Nat Hist 2006, 299:1-262.

12. Brown JL, Twomey E, Amezquita A, DeSouza MB, Caldwell J, Lötters S, May RVON, Melo-sampaio PR, Mejía-vargas D, Perez-peña P, Pepper M, Poelman EH, Amézquita A, Souza MB D, Caldwell JP, Von MR, Perez- P, Sanchezrodriguez M, Summers K: A taxonomic revision of the Neotropical poison frog genus Ranitomeya (Amphibia: Dendrobatidae). Zootaxa 2011, 3083:1-120.

13. Saporito RA, Spande TF, Martin Garraffo H, Donnelly MA: Arthropod Alkaloids in Poison Frogs: A Review of the "Dietary Hypothesis". Heterocycles 2009, 79:277.

14. Summers K, Cronin TW, Kennedy T: Variation in spectral reflectance among populations of Dendrobates pumilio, the strawberry poison frog, in the Bocas del Toro Archipelago, Panama. J Biogeogr 2003, 30:35-53.

15. Sherratt TN: The evolution of Müllerian mimicry. Naturwissenschaften 2008, 95:681-95.

16. Noonan BP, Comeault AA: The role of predator selection on polymorphic aposematic poison frogs. Biol Lett 2009, 5:51-54.

17. Chouteau M, Angers B: The role of predators in maintaining the geographic organization of aposematic signals. Am Nat 2011, 178:810-7.

18. Comeault AA, Noonan BP: Spatial variation in the fitness of divergent aposematic phenotypes of the poison frog, Dendrobates tinctorius. J Evol Biol 2011, 24:1374-9.

19. Saporito RA, Donnelly MA, Jain P, Martin Garraffo H, Spande TF, Daly JW: Spatial and temporal patterns of alkaloid variation in the poison frog Oophaga pumilio in Costa Rica and Panama over 30 years. Toxicon 2007, 50:757-78.

20. Saporito RA, Donnelly MA, Madden AA, Garraffo HM, Spande TF: Sex-related differences in alkaloid chemical defenses of the dendrobatid frog Oophaga pumilio from Cayo Nancy, Bocas del Toro, Panama. J Nat Prod 2010, 73:317-21.

21. Schulte R: Eine neue Dendrobates_art aus ostperu (Amphibia: Salienta: Dendrobatidae). Sauria 1986, 8:11-20.

22. Symula R, Schulte R, Summers K: Molecular phylogenetic evidence for a mimetic radiation in Peruvian poison frogs supports a Müllerian mimicry hypothesis. Proc Biol Sci 2001, 268:2415-21.

23. Symula R, Schulte R, Summers K: Molecular systematics and phylogeography of Amazonian poison frogs of the genus Dendrobates. Mol Phylogenet Evol 2003, 26:452-475.

24. Yeager J, Brown JL, Morales V, Cummings M, Summers K: Testing for selection on color and pattern in a mimetic radiation. Curr Zool 2012, 58:668-676

25. Twomey E, Yeager J, Brown JL, Morales V, Cummings M, Summers K Phenotypic and Genetic Divergence among Poison Frog Populations in a Mimetic Radiation. PLoS One 2013, 8:e55443. 
26. Chouteau M, Summers K, Morales V, Angers B: Advergence in Müllerian mimicry: the case of the poison dart frogs of Northern Peru revisited. Biol Lett 2011, 7:796-800.

27. Mallet J, Gilbert LE: Why are there so many mimicry rings? Correlations between habitat, behaviour and mimicry in Heliconius butterflies. Biol J Linn Soc 1995, 55:159-180.

28. Merrill RM, Jiggins CD: Müllerian mimicry: sharing the load reduces the legwork. Curr Biol 2009, 19:R687-9.

29. Stuckert AMM, Venegas PJ, Summers K: Experimental evidence for predator learning and Müllerian mimicry in Peruvian poison frogs (Ranitomeya, Dendrobatidae). Evol Ecol 2013, 28(3):413-426.

30. Schaefer $H$, Vences M, Veith M: Molecular phylogeny of Malagasy poison frogs, genus Mantella (Anura: Mantellidae): homoplastic evolution of colour pattern in aposematic amphibians. Org Divers Evol 2002, 2:97-105.

31. Prates I, Antoniazzi MM, Sciani JM, Pimenta DC, Toledo LF, Haddad CFB, Jared C: Skin glands, poison and mimicry in dendrobatid and leptodactylid amphibians. J Morphol 2012, 273:279-90.

32. Speed MP: Muellerian mimicry and the psychology of predation. Anim Behav 1993, 45:571-580.

33. Rowland HM, Ihalainen E, Lindström L, Mappes J, Speed MP: Co-mimics have a mutualistic relationship despite unequal defences. Nature 2007, 448:64-7.

34. Brown JL, Twomey E, Morales V, Summers K: Phytotelm size in relation to parental care and mating strategies in two species of Peruvian poison frogs. Behaviour 2008, 145:1139-1165.

35. Andriamaharavo NR, Garraffo HM, Saporito RA, Daly JW, Razafindrabe CR, Andriantsiferana M, Spande TF: Roughing it: a mantellid poison frog shows greater alkaloid diversity in some disturbed habitats. J Nat Prod 2010, 73:322-30

36. Mallet J, Joron M: Evolution of Diversity in Warning Color and Mimicry: Polymorphisms, Shifting Balance, and Speciation. Annu Rev Ecol Syst 1999, 30:201-233.

37. Blount JD, Speed MP, Ruxton GD, Stephens PA: Warning displays may function as honest signals of toxicity. Proc R Soc Biol Sci 2009, 276:871-877.

38. Lee TJ, Speed MP, Stephens PA: Honest signaling and the uses of prey coloration. Am Nat 2011, 178:E1-9.

39. Santos JC, Cannatella DC: Phenotypic integration emerges from aposematism and scale in poison frogs. Proc Natl Acad Sci U S A 2011, 108:6175-80.

40. Brower LP, Brower JVZ, Corvino JM: Plant poisons in a terrestrial food chain. Proc Natl Acad Sci U S A 1967, 57:893-898.

41. Speed MP, Ruxton GD, Broom M: Automimicry and the evolution of discrete prey defences. Biol J Linn Soc 2006, 87:393-402.

42. Saporito RA, Isola M, Maccachero V, Condon K, Donnelly MA: Ontogenetic scaling of poison glands in a dendrobatid poison frog. J Zool 2010, 282:238-245.

43. Ruxton GD, Sherratt TN, Speed MP: Speed MP. Avoiding Attack: The Evolutionary Ecology of Crypsis, Warning Signals and Mimicry 2004, 17:249.

44. Daly JW, Spande TF, Garraffo HM: Alkaloids from amphibian skin: a tabulation of over eight-hundred compounds. J Nat Prod 2005, 68:1556-75.

doi:10.1186/1471-2148-14-76

Cite this article as: Stuckert et al:: Alkaloid defenses of co-mimics in a putative Müllerian mimetic radiation. BMC Evolutionary Biology $201414: 76$.

\section{Submit your next manuscript to BioMed Central and take full advantage of:}

- Convenient online submission

- Thorough peer review

- No space constraints or color figure charges

- Immediate publication on acceptance

- Inclusion in PubMed, CAS, Scopus and Google Scholar

- Research which is freely available for redistribution

Submit your manuscript at www.biomedcentral.com/submit
Ciomed Central 